\title{
A escala e a medida. A criação de ponto de vista em dois poemas de Prosas seguidas de Odes mínimas, de José Paulo Paes
}

\author{
Scale and Measure. \\ On the creation of a view point in two poems of José Paulo Paes's \\ Prosas seguidas de Odes mínimas
}

Carolina Lindenberg Lemos

Universidade de São Paulo - São Paulo - Brasil

$\diamond$

Resumo: A crítica de José Paulo Paes reconheceu-lhe um caráter minimalista. Este artigo busca na noção de aspecto os instrumentos para a explicitação dessa percepção. Para além da constatação do tamanho dos poemas e versos, o conteúdo também constrói um universo minimalista. Ao imprimir recortes e saliências, o aspecto instaura um sujeito observador: um ponto de vista, que dará a medida diminuta dos objetos convocados. Os recortes da minimalidade aspetual em dois poemas de Prosas seguidas de Odes mínimas se construirão tanto no tempo - campo tradicional do aspecto linguístico - quanto nas categorias de espaço e pessoa. As saliências dos recortes aspectuais ganharão paulatinamente figuras de atenuação e aproximação do sujeito, construindo a chave da leitura minimalista e desencadeando também a leitura metalinguística dos poemas. Além de explicitar os procedimentos do fazer poético de Paes, esta análise traz operacionalidade à noção de aspecto estendida às categorias de pessoa, tempo e espaço.

Palavras-chave: Ssemiótica; Poética; Aspecto; Categorias discursivas

\begin{abstract}
The critics of José Paulo Paes have recognized a minimalist aspect in his work. This paper looks at the notion of aspect as a tool to explain such perception. Beyond the size of poems and verses, the content also builds a minimalist universe. By imprinting boundaries and relief, an observer comes into play: a point of view, that will offer the minimal measure of the objects called forth. The minimal aspect in two poems in Prosas seguidas de Odes mínimas is founded in time - which houses the traditional linguistic aspect - as well as in the categories of space and person. The reliefs created are progressively attenuated and the figures are brought to the scale of the subject, building thus the key to the minimalist reading, and ultimately triggering a meta-linguistic reading of the poems. Finally, and in addition to the exploration of the semiotic procedures underlying the poetics of Paes, our analytic exercise shows how one may operate with the discursive extensions of the notion of aspect to the categories of person, time and space.
\end{abstract}

Keywords: Semiotics; Poetics; Aspect; Discursive categories

Les petits faits inexpliqués contiennent le renversement des explications des grands faits.

Paul Valéry 


\section{Introdução}

Ao percorrer os poemas da primeira parte de Prosas seguidas de Odes mínimas, de José Paulo Paes, somos apresentados a uma série de começos, fins, passagens, mudanças. Já o primeiro texto nos introduz uma perspectiva de fim desde o título: "Escolha de túmulo", mas, ao mesmo tempo, revela uma abertura para um início numa fiada de figuras que analisaremos mais à frente.

As tensões entre elementos incoativos e terminativos nos remete à noção linguística de aspecto. Segundo o primeiro tomo do Dicionário de semiótica de Greimas e Courtés (2011, p.39-40), a aspectualidade está ligada a uma sobredeterminação do tempo, ou seja, ao instaurar pontualidades, duratividades, começos, meios e fins, o enunciador recorta a matéria narrada transformando-a em processos.

Para os autores, o processo de aspectualização é "a disposição, no momento da discursivização, de um dispositivo de categorias aspectuais mediante as quais se revela a presença implícita de um actante observador" (GREIMAS; COURTÉS, 2011, p.39). Ora, a definição de Greimas e Courtés vai além do recorte dos processos e põe em jogo a figura de um observador. Colocada dessa forma, a aspectualidade aparece fortemente associada à questão do ponto de vista nos textos. No segundo tomo do Dicionário de Semiótica, que surge com a proposta de expandir as noções mais sedimentadas do primeiro, Françoise Bastide (1986, p. 19-20) propõe entender esse observador, pressuposto necessário à noção de aspecto, como gerador de uma escala, uma medida antropomorfa. A suposição de que há um observador que organiza os fluxos do texto estabelece parâmetros para enxergar os elementos descritos nos poemas.

Esse observador de que tratamos aqui está, por exemplo, na raiz da constatação que faz Antonio Carlos Secchin (1996, p. 122-123) acerca de dois poemas da segunda parte de Prosas seguidas de Odes mínimas: "Treze poemas integram a segunda parte do livro, 'Odes mínimas', num espectro que compreende desde a microscopia um tanto preciosa de 'O alfinete' - [...] - até o macrocosmo de 'Ao Shopping Center'".

Nesse caso, ainda poderíamos dizer que o autor faz apenas uma oposição entre dois objetos de dimensões enormemente diferentes: um alfinete e um shopping center. Entretanto, para a comparação, lança mão da expressão "microscopia" e temos já aí o olhar na raiz da palavra. Também no trecho seguinte: "Esse espectro abrange uma série de objetos contíguos ao escritor ('À bengala'; 'Aos óculos'; 'À tinta de escrever')" (SECCHIN, 1996, p. 123), vemos a escala humana convocada pela menção ao escritor. Ainda que o crítico de Paes estivesse fazendo referência a elementos extratextuais do contexto imediato do poeta, esses objetos foram inseridos nos poemas de tal forma a criar esse simulacro de aproximação cotidiana, portanto dando a ver ao leitor objetos que, passado o momento suposto de enunciação, mais uma vez se fazem presentes por meio do texto.

Dessa forma, a noção de aspecto pode nos ajudar a investigar, por meio da análise de dois poemas da primeira parte de Prosas seguidas de Odes mínimas, de que forma está recortado o fluxo temporal e suas relações com o estabelecimento de um ponto de vista. Buscaremos, assim, nas noções de aspecto, observador, escala, uma formulação possível para corroborar essa característica minimalista do poeta de que tanto falam seus críticos. ${ }^{1}$ Para além da constatação de que os poemas são breves em sua forma, a investigação do ponto de vista e a incorporação de um valor escalar podem trazer às claras a aproximação do pequeno também no conteúdo.

\section{"Escolha de túmulo" ou sobre o aspecto}

Em “Um poeta em paz", Secchin aponta o curioso contraste de um livro que abre com um poema que se chama "Escolha de túmulo" e fecha com "A um recémnascido", como se o livro iniciasse pelo fim e terminasse com a perspectiva de um começo. Logo em seguida, o autor traz à baila o fato de que, apesar do título - "pista falsa", em suas palavras -, no poema de abertura "persiste o desejo de que, em meio ao dano, algum saldo seja possível" (SECCHIN, 1996, p. 124).

\section{Escolha de túmulo \\ Mais bien je veux qu'un arbre m'ombrage au lieu d'un marbre. Ronsard}

\begin{abstract}
Onde os cavalos do sono batem cascos matinais.

Onde o mundo se entreabre em casa, pomar e galo.

Onde ao espelho duplicam-se as anêmonas do pranto.

Onde um lúcido menino propõe uma nova infância.
\end{abstract}

Ali repousa o poeta.

Ali um vôo termina, outro vôo se inicia.

(PAES, 2008, p. 361)

\footnotetext{
São exemplos dessa visão sobre a obra de José Paulo Paes: a "concisão telegráfica" apontada por Bosi (2003, p. 162); a "dimensão infinitamente pequena" para Arrigucci Jr. (1999, p. 200); o interesse radical pela "brevidade poética" segundo Fortuna (1991, p. 84); e o "poeta do pouco" para Secchin (1996, p. 122).
} 
Está de fato colocada, no título, a perspectiva de fim. $\mathrm{O}$ viés persiste na citação do poema "Le tombeau" de Ronsard. No entanto, já nessa epígrafe percebemos uma primeira alusão à vida na escolha do poeta renascentista por um túmulo vivo, que se opõe à mineralidade morta do mármore. Se essa ainda parece uma sugestão distante, a análise paulatina dos versos nos mostrará a construção dessa escolha pela vida.

A primeira estrofe do poema tende à terminatividade. O "sono" seguido da manhã (em "cascos matinais") poderia nos levar a imaginar uma história que termina, o fim de uma história noturna (especialmente se levados pela figura do túmulo que abriu o texto). Entretanto, a manhã também pode ser entendida como uma figura do começo. Na passagem da noite para o dia, do sono à vigília, fica marcada uma transição que se confirmará nas próximas estrofes.

Dessa transição sugerida, passamos a figuras incoativas como o mundo que "se entreabre em casa, pomar e galo" e a proposta de "uma nova infância". ${ }^{2}$ Há em seguida uma parada na duração de "Ali repousa o poeta". Essa quinta estrofe faz uma transição aspectual: de elementos incoativos passamos a um estativo. A mudança na escolha aspectual parece indicar uma virada no texto. Assim, o fluxo do texto conduzido pelas variações aspectuais propõe um início de continuidades e temporalidades originantes (ZILBERBERG, 2006, p. 132-140). Em seguida, a entrada da duratividade no repouso do poeta produz uma parada expectante, que prepara a retomada do fluxo na última estrofe-síntese: "Ali um voo termina, / outro voo se inicia".

As imagens de fim e começo podem ser lidas como nascimento e morte. E o desencadeador dessa leitura seria o próprio título. No entanto, a entrada do poeta na quinta estrofe (além de sugestões em termos como "sono", "nova infância", "voo") marca a leitura figurada. Esse poema que se anunciara um fim, revela-se na verdade um recomeço, uma proposta para a poética que encontraremos no decorrer do livro. Pois, como apontou Pasche $(2009$, p. 85$)$, esse é um livro diferente na obra de Paes, mais intimista, com remissões a conversas e diálogos (SECCHIN, 1996, p. 121).

Por outro lado, apesar de permeado de fins, inícios e viradas, elas não são construídas de forma brusca pelo

\footnotetext{
$2 \mathrm{Na}$ terceira estrofe, ainda que se possa imaginar um choro que brota na frente do espelho, a figura escolhida por Paes está mais ligada a um aumento (duplicação) e, assim, talvez dissesse mais respeito a uma aspectualidade durativa. $\mathrm{O}$ uso do espelho e de suas possibilidades multiplicadoras vai reaparecer em "Odes Mínimas" no poema "Ao Espelho". O título deste último é ambíguo e tanto pode, como nas demais odes, estar sendo endereçado ao espelho, como também fazer referência ao ato de se colocar em frente ao espelho. No poema de "Prosas", o autor não põe em questão o poder multiplicador do instrumento, apenas constata o aumento do pranto. Em "Odes Mínimas", o tom é todo outro e a sutil ironia faz com que venha às claras a superficialidade do jogo de visada.
}

poeta. A escolha pelo tempo presente dos verbos escande o tempo, de forma que mesmo as transições ganham duração e alguma lentidão (em oposição ao que seria uma construção num pretérito perfeito tão carregado de passagens bruscas). Dessa forma, a transformação da poética adquire suavidade na passagem gradual, contribuindo para a delicadeza e a naturalidade do texto que, como mencionamos acima, é a tônica de "Prosas". A gradualidade de "Escolha de túmulo" contrasta, então, com a urgência que vemos imprimida em "À tinta de escrever" de "Odes mínimas". Apesar de falar de um desejo de duração, neste último, o poeta encerra na rapidez entrecortada de: "firma, azul, a tua promissória / ao minuto e adeus que agora tudo é História".

Em "Escolha de túmulo", as demarcações aspectuais são sentidas nas figuras de começo e de abertura, como a manhã, o pomar, a infância. A força da abertura é atenuada, como vimos, pelo alongamento temporal do verbo presente, mas também pela repetição da fórmula adverbial ("onde") que abre as estrofes, criando uma ciclicidade. $\mathrm{O}$ ciclo retem o desenvolvimento narrativo. Ao reconhecermos a repetição, percebemos uma regra de retorno ao mesmo ponto em cada estrofe, gerando equivalência entre elas. A insistência na repetição faz surgir uma expectativa de mudança, de uma quebra da circularidade.

A interrupção do girar surge na estaticidade do poeta que repousa (palavra também bastante atenuada em contraste com o túmulo do título). Há, nesse ponto, uma mudança no andamento do poema. A última estrofe é, assim, a retomada da abertura na figura do voo. Porém, não mais estamos envoltos num ciclo que, se por um lado propõe aberturas, por outro recai no mesmo reinício a cada estrofe, sem maiores progressos. A última estrofe é um outro começo. É o começo a partir de uma outra fórmula ("ali"), aquela que se usou para deixar para trás o poeta em repouso, o voo que terminou. Ao deixar esse voo em aberto, apenas iniciado, cria-se uma perspectiva poética para todos os outros poemas do livro que começa. A morte do poeta abre para uma espécie de transcendência, mas não a metafísica, e sim uma possibilidade de recriação poética (PASCHE, 2009, p. 93).

\section{"Ceia" ou do aspecto ao observador}

Voltando à observação de Secchin acerca do primeiro e do último poema de Prosas seguidas de Odes mínimas, constatamos que de fato, nos dois textos, está colocada mais a perspectiva de abertura do que de fechamento. No entanto, dada a diferença de construção e tom entre as duas partes do livro, achamos por bem tomar como encerramento não aquele que fecha "Odes mínimas", mas o poema de conclusão de "Prosas". 


\section{Ceia}

Pesca no fundo de ti mesmo o peixe mais luzente. Raspa-lhe as escamas com cuidado: ainda sangram. Põe-lhe uns grãos do sal que trouxeste das viagens e umas gotas de todo o vinagre que tiveste de beber na vida.

Assa-o depois nas brasas que restem em meio a tanta cinza.

Serve-os aos teus convivas, mas com pão e vinho do trigo que não segaste, da uva que não colheste mas que de alguma forma foram pagos em tempo ainda hábil pelo teu muito suor e por um pouco do teu sangue.

Não te desculpes da modéstia da comida.

Ofereceste o que tinhas de melhor.

Podes agora dizer boa-noite, fechar a porta, apagar a luz

e ir dormir profundamente. Estamos quites tu e eu, teu mais hipócrita leitor.

(PAES, 2008, p. 388).

Como "Escolha de túmulo", o título "Ceia" sugere um aspecto terminativo: a última refeição da noite, a última refeição de Cristo. ${ }^{3}$ Essa perspectiva continua nas figuras da experiência e do fim como "o vinagre que tiveste de beber na vida", o suor e o sangue do trabalho já realizado e as cinzas que restaram. Nessas duas primeiras estrofes, a terminatividade é contemporizada pela presença do injuntivo, que abre para um percurso futuro. O poema é quase uma receita que programa um fazer ao leitor.

Aliás, todo o poema é construído em meio à relação de mais e menos, como em constante ajustamento e atenuação (ZILBERBERG, 2006, p. 46-51,118). Na primeira figura da pesca e da raspagem do peixe, somos apresentados a uma brevidade temporal na experiência recente marcada por "ainda sagram". Essa aproximação temporal é atenuada pelas imagens de um passado mais distante que apreendemos a partir de um alongamento do tempo no plural das viagens e nos modificadores em "todo o vinagre" e "toda cinza".

$\mathrm{Na}$ segunda estrofe, há uma alusão a uma quase insuficiência, uma falta que parece estar ligada a um distanciamento das origens dos alimentos ofertados: o eulírico não segou o trigo e não colheu a uva. Novamente, o que poderia gerar uma amplificação de tensão é logo em seguida relativizado com a entrada da paga com o trabalho. A falta é anunciada e imediatamente reparada. Mesmo a figura do trabalho aparece com essa tônica no aumento em "muito suor" e na reparação de "um pouco de sangue". A imagem mais corriqueira do suor é aumentada, enquanto a expressão que implicaria a invasão e a ferida do corpo é diminuída.

$\mathrm{Na}$ terceira estrofe, a falta ressurge na comida insuficientemente modesta. Desta vez do menos para o mais, a reparação vem na aceitação de que o pouco é o melhor que há para ser ofertado. Nesses aumentos e diminuições, os ajustamentos parecem criar uma flutuação de expectativas que vai reger a timia do leitor. Essas variações são o próprio agenciamento do aspecto construído não em termos verbais, mas discursivos. Segundo Zilberberg (1995, p.224), “a aspectualização semiótica rebate os afetos do sujeito sobre o objeto e o apreende comme excessivo ou defectivo". ${ }^{4}$

Dizíamos que a terminatividade proposta no título e nas imagens de um viver já passado encontrava um contraponto nos imperativos de um fazer futuro no corpo do poema. A lógica da conclusão é, entretanto, implacável e, à ceia, segue-se a noite. O sono, que em "Escolha de túmulo" aparecia no início sendo seguido pela manhã, ${ }^{5}$ agora vem ao final no encerramento do dia. Os gestos de finalização em: "Podes agora dizer boa-noite, fechar a porta, apagar a luz" lembram a "Consoada" de Bandeira (1993, p.223): "Encontrará lavrado o campo, a casa limpa, / A mesa posta, / Com cada coisa em seu lugar".

Em conhecido ensaio, Arrigucci Jr. (1990, p. 257-275) aponta diversos elementos da construção do poema de Bandeira que parecem encontrar eco ou resposta nessa outra consoada de José Paulo Paes. Vemos já nesse trecho citado a repetição de lugares comuns. Apesar da escolha de diferentes expressões, tanto a lista de Bandeira quanto a de Paes se encontram na coloquialidade das frases feitas e no paralelismo das construções. Segundo o crítico, a generalidade das expressões associada à simplicidade e à ciclicidade da repetição ${ }^{6}$ seriam uma forma de aproximação do incompreensível (ARRIGUCCI JR., 1990, p. 267).

O tema da morte recebe também em ambos formulação a partir da figura do sono e da noite. Por si só, essa fórmula é comum demais na literatura para justificar o paralelo. Como apontamos no parágrafo anterior, é uma semelhança de procedimentos que os aproxima, mas também a escolha de tom. Dizíamos que Paes constrói um tom moderado, que não tende nem para a nulidade nem para o paroxismo. Da mesma forma, "Consoada" busca a temperança e a humildade no tratamento da morte.

\footnotetext{
Encontraremos mais referências à Santa Ceia no pão e vinho mencionados na segunda estrofe.

4 Nossa tradução para: "l'aspectualisation sémiotique rabat les affects du sujet sur l'objet en l'appréhendant comme excessif ou défectif'

5 Da mesma forma, podemos entender o repouso do poeta, na quinta estrofe, como a presença do "sono". Nesse caso, seria seguida também de um elemento incoativo no voo que se inicia.

6 Apesar de não crermos ser pertinente uma comparação direta do poema de Bandeira com "Escolha de túmulo", é curioso notar uma semelhança de procedimentos na construção de uma repetição cíclica. Ao criar uma regra, a repetição parece nos levar ao conforto do conhecido e esperado, como na observação de Arrigucci Jr. Por outro lado, a falta de progresso pode gerar uma demanda por uma resolução que venha quebrar a ciclicidade e uma proposta de desfecho para o texto. Para uma discussão mais detalhada dos efeitos da repetição, ver LEMOS, Carolina Lindenberg; TATIT, Luiz Augusto de Moraes (2010, p. 79-96).
} 
Em ambos, encontramos um balanço positivo para uma morte sem perspectiva de transcendência (trataremos do desfecho em mais detalhes numa outra comparação mais adiante).

Por outro lado, perceberemos um contraste de atitudes na relação com o campo e a natureza. Arrigucci Jr. insiste por todo o seu ensaio no caráter de idílio bucólico do poema bandeiriano e no papel da relação do eu-lírico com a natureza na construção da simplicidade e da familiaridade com a morte e, até mesmo, como uma negação do processo de reificação por que passa o homem moderno. "Ceia" parece se opor a essa postura no momento em que declara:

Serve-os aos teus convivas, mas com pão e vinho
do trigo que não segaste, da uva que não colheste
mas que de alguma forma foram pagos
em tempo ainda hábil
pelo teu muito suor e por um pouco do teu sangue.

Esse trecho - já citado anteriormente - traz aqui um novo elemento. Vemos uma negação direta do trabalho no campo e uma afirmação das relações de capital na paga pela mercadoria por meio de um trabalho de outra ordem, mas que também implica o sacrifício do suor e do sangue. Podemos aventar aqui uma diferença de gerações na forma de encarar as vicissitudes capitalistas - afinal, os poemas estão separados por mais de meio século. A perspectiva do idílio, do retorno ao campo parece bastante mais próxima ao poeta modernista.

Uma diferença de gerações frente às possibilidades de sonhos e ideais parece ser tema de um outro poema de "Prosas". Em "Sobre o fim da história", vemos três atitudes retratadas: uma primeira (clássica?) em que os valores estão dados e o mundo pronto a ser conquistado; a segunda em que o sonho e a ilusão, na forma dos moinhos quixotescos, ainda são possíveis; e o terceiro movimento, em que tem plena consciência o poeta de que não há nem mesmo os moinhos e a reconstrução dos inimigos é a única chance de uma retomada de direção. A segunda posição de "Sobre o fim da história" toca no idílio bandeiriano. Como os gigantes que são moinhos, o campo de Bandeira é feito do sonho pastoral.

No penúltimo verso: "e ir dormir profundamente. Estamos quites", um outro Bandeira (1993, p.139-140) se insinua: "Estão todos deitados / Dormindo / Profundamente". Novamente, é um ensaio de Arrigucci Jr. (1990, p. 201-232) que nos trará elementos de comparação entre Bandeira e Paes. Em "Profundamente", o sono aparece como figura da morte. Porém, são os elementos de construção que, mais uma vez, justificam o paralelo.

Segundo Arrigucci Jr. (1990, p.222-223), o tema do Ubi sunt?, mais claramente colocado em "Profundamente", pode ser entendido em sentido mais amplo como uma forma de aprender a morrer e o sono seria a forma de mediação que mantém a morte próxima e familiar. Apesar de o motivo não estar colocado nos mesmos termos em "Ceia", seus desdobramentos em forma de meditação sobre a morte parecem centrais para o poema. Essa aproximação da morte, em Bandeira como em Paes, se dá por meio de uma representação em tom humilde do cotidiano.

Também em ambos os poemas, vemos referências ao texto religioso cristão (na festa de São João e na Santa Ceia) transformadas pelo materialismo moderno de tal forma a negar a transcendência e a infinitude de uma alma imortal (ARRIGUCCI JR., 1990, p.232). A forma seca e elíptica que Arrigucci Jr. (1990, p.220) aponta em Bandeira lembra em muito o que o mesmo crítico reconhece na dicção de Paes (ARRIGUCCI JR., 1999, p. 188). Em ambos, o procedimento de condensação leva ao efeito de uma expansão da emoção e a criação dessa visão de mundo materialista. Seja por via de uma rememoração de entes queridos ("Profundamente") ou pela referência direta ao eu-lírico ("Consoada" e "Ceia"), a morte se construirá como um "balanço autobiográfico da existência individual” (ARRIGUCCI JR., 1990, p. 220) e a fórmula feita - dormir profundamente - uma vez recriada por Bandeira, vai ganhar ainda mais uma formulação em Paes.

Outro aspecto de construção formal de "Profundamente" está mais intimamente ligado às relações de ponto de vista que vimos tratando nos poemas de José Paulo Paes. Há um procedimento próximo da ficção que está posto em marcha no poema de Bandeira.

Percebe-se então a função ficcionalizadora da cena, que apresenta ou mostra um espaço humanizado, onde as coisas existem para o homem: exatamente como na prosa de ficção, em que o espaço costuma estar em função da personagem, cuja entrada em cena define o caráter de não-realidade do mundo ficcional. (ARRIGUCCI JR., 1990, p. 209)

Em "Ceia", também nos deparamos com uma "cena de ficção". A receita para a ceia cria a figura da refeição que se prepara e da mesa posta. Vemos paulatinamente construir-se, a partir da junção de fragmentos de uma vida, um sentido na possibilidade da constituição de um conjunto. É na reunião dos vestígios de um trajeto que o conteúdo toma forma. O poema produz uma transferência de escalas. Partimos do grande alongamento temporal de todas as experiências de uma vida que vão se concentrando no tempo de uma refeição. A nenhum sujeito é dado enxergar de um golpe todo o fluxo de uma vida, mas, ao incutir a cada objeto da mesa o registro de tanta experiência, o poeta insere o enorme no mínimo ou, ao contrário, abre o pequeno para o universal. 
José Luiz Fiorin (2002,p. 42) reconhece três instâncias em jogo na instauração de uma enunciação: "Como a pessoa enuncia num dado espaço e num determinado tempo, todo espaço e todo tempo organizam-se em torno do 'sujeito', tomado como ponto de referência." Pessoa, tempo e espaço constituem elementos pressupostos pelo próprio ato de enunciar, mas também se configuram como organizadores do texto.

Nesse poema de Paes, como também nas relações mais globais que estamos tentando traçar, não se trata apenas da criação de uma figura do tempo nos traços de uma experiência passada, do espaço da mesa e do forno e da pessoa realizada num suposto leitor que deve realizar o programa proposto da ceia. Buscamos essas instâncias da enunciação na configuração de um ponto de vista revelado nas escolhas de recortes e limites que podemos reconhecer, ou seja, não na sua realização de superfície, mas nos fluxos subjacentes às figuras manifestantes. Dessa forma, vimos que o tempo está agenciado por relações de proximidade e distância, elementos finais e rastros de continuidade do passado. O espaço também é regido por aproximações, opostas aos alongamentos aludidos nos percursos de viagens e da vida que agora se fecham em torno de uma mesa.

Falta, porém, encontrar a profundidade no terceiro elemento: a pessoa. A citação de Fiorin destacada acima, além de apresentar os três elementos enunciativos, revela uma centralidade na pessoa que se constitui como um ponto de referência ("Assim, espaço e tempo estão na dependência do $e u$, que neles se enuncia"-FIORIN, 2002, p. 42). São justamente os versos finais que vão colocar em perspectiva o papel do sujeito e dar-lhe a medida de seu lugar no poema: "e ir dormir profundamente. Estamos quites / tu e eu, teu mais hipócrita leitor."

O enjambement é central no efeito final. "Estamos quites" em meio a referências à morte e às alusões a Bandeira pode nos deixar imaginar num átimo que se trata de uma conversa com a morte, como na "Consoada". Ou ainda, pode ser um acerto de contas com um terceiro, trazido para o poema pela segunda pessoa. Numa comparação com outros poemas do livro, podemos pensar numa retomada de alguma figura significativa, como o pai de "Um retrato", poema que fala exatamente de um ajuste possível depois da morte. No entanto, novamente quem aparece são "tu" e "eu". Partículas "vazias" de conteúdo, ${ }^{7}$ só ganham sentido por meio da enunciação,

\footnotetext{
7 Na verdade, os dêiticos não são completamente vazios de conteúdo semântico. Há alguma codificação ligada ao número e ao gênero (no caso da terceira pessoa) e uma certa "instrução de apontamento", em outras palavras, sabemos que "eu" aponta para quem fala, "tu" para a outra ponta do diálogo, "ele" para fora da situação de comunicação. A ideia de que os dêiticos são vazios vem da flexibilidade que têm de se referir a sujeitos os mais díspares. Fiorin (2002: 42-43) sugere alguns exemplos bastante diversos.
}

preenchidas pelos valores do contexto em que estão inseridas.

"Eu" e "tu" já estavam colocados desde a configuração de um diálogo no início do poema. O que se segue na linha é uma qualificação: "teu mais hipócrita leitor". Paes joga com a reversibilidade da referência da primeira e segunda pessoas num diálogo (FIORIN, 2002, p. 41). Nesse movimento, aquele que escreve é também aquele que lê. $\mathrm{O}$ truque de espelhos cria uma linguagem reflexiva e o poema passa a ser uma conversa consigo mesmo. Num retorno ao início, aquele a quem o poeta precisa convencer, por meio da exortação à realização de um fazer que ao mesmo tempo instaura a ceia e fecha a vida, é no fundo a si mesmo. É um balanço de sua própria vida. ${ }^{8}$ Há, assim, uma nova aproximação, mas dessa vez não temporal ou espacial. Aquele sujeito a quem o poeta falava da outra ponta do canal de comunicação está agora do lado de dentro. A enunciação, de ordinário partida em dois - enunciador e enunciatário -, se vê novamente fundida num só.

\section{Conclusão}

Ao laçar as duas pontas de "Prosas", detemo-nos na brevidade de poemas que formam, na verdade, duas poéticas. Construções em certas dimensões convergentes, em outras divergentes, "Ceia" e "Escolha de túmulo" tocam na predileção do poeta pelo mínimo. $\mathrm{O}$ caminho que escolhemos para colocar em relevo essa tônica da poesia de Paes foi a do aspecto. Não nos interessa, porém, apenas o traço aspectual que está inscrito no verbo num passado inacabado em oposição ao passado acabado, por exemplo. Reconhecemos que a aspectualidade pode (e deve) ser tomada como uma estratégia discursiva de regulagem de saliências e passagens. Assim, se percebemos uma estratégia, há um sujeito pressuposto que serve de medida ou parâmetro para que as variações de fluxo se deixem sentir. Esse sujeito que aqui parece ser apenas um construto teórico foi paulatinamente se revelando no confronto com as figuras reclamadas nos textos.

$\mathrm{O}$ aspecto em "Escolha de túmulo" se fez evidente nas figuras salientes de início, mas foi atenuado pela gradação do verbo no presente e pela repetição. Em "Ceia", impera a terminatividade na figura da morte fechando o poema, mas sua força é também atenuada pelo balanço positivo e pelas construções de familiaridade.

\footnotetext{
8 Mais uma vez, vemos relação com a "Consoada". No poema de Bandeira, o balanço consigo mesmo está mais claro. Não nos perguntamos em momento algum de quem é a casa arrumada. O diálogo com a morte é apenas o último fechamento da série de conclusões expressas na lista. O diálogo consigo mesmo em Paes não é a conclusão, mas o caminho necessário para chegar à conclusão. Assim, o diálogo adquire funções bastante distintas num e noutro poema.
} 
Dessa forma, se estão postas dominâncias aspectuais opostas: o incoativo no primeiro poema e o terminativo no último, os procedimentos de construção aspectual são semelhantes. Em ambos, as atenuações colaboram com o tom menor que evita as grandiloquências e o poeta trata do fazer poético, da vida e da morte num registro mais próximo à escala do sujeito.

Por outro lado, num parâmetro mais ligado à espacialidade, vimos em "Ceia" uma transferência de escala, que, talvez de forma mais direta que na temporalidade, reforça a presença de um sujeito que instaura a escala antropomorfa. Assim, grandes dimensões foram transpostas para as figuras familiares da ceia. Esse gênero de transposição também pode ser encontrado em "Escolha de túmulo", por exemplo em "Onde o mundo se entreabre / em casa, pomar e galo". Novamente, somos apresentados a uma estratégia de inserção de grandes dimensões no mínimo típico da poesia de Paes.

Enfim, se o espaço e o tempo estão recortados em processos pelo olhar organizador do sujeito, resta agora inverter as perspectivas e perguntar pelo lugar do sujeito em meio aos processos. Secchin (1996, p. 121) sugere que "Prosas" é uma "obra de reencontros e despedidas" e o crítico parece estar se referindo a poemas que relembram figuras do passado do poeta, como o próprio "Reencontro", com Osman Lins, ou "A casa", onde aparecem pai, avô, tio, ou ainda os sete poemas "sem versos" dedicados a diferentes figuras de seu passado. A sugestão de Secchin é instigante e ganha outro sentido nos poemas que não tratam diretamente de personagens da história pessoal do poeta. "Escolha de túmulo" também é uma despedida. Apesar de escrito em terceira pessoa, podemos facilmente ler o poema em registro metalinguístico, e nesse caso teríamos um poeta que se despede de si mesmo. A terceira pessoa seria uma estratégia de distanciamento ${ }^{9}$ dessa poética anterior, de que não temos muitos detalhes e que ficou para trás em favor dessa outra que se inicia para o restante do livro.

Em "Ceia", a opção é pela primeira e segunda pessoas. A construção do diálogo, se mais próximo quando comparado com a terceira pessoa de "Escolha de túmulo", ainda guarda uma distância a ser transposta. Como vimos na análise, o verso final embaralha as referências e o "tu" e o "eu" se confundem no mesmo sujeito. Assim, se o poema de abertura foi a despedida de uma certa poesia, o poema final é o reencontro do poeta consigo mesmo, ou o encontro de uma nova poética.

Os espelhamentos na forma do conteúdo dos nossos poemas de eleição deixam ver estratégias distintas, e por

\footnotetext{
9 Para o uso da terceira pessoa como estratégia de deslocamento do "centro da cena", ver Secchin (1996, p. 122)
}

vezes quase opostas, para a construção de um mesmo mínimo. Dizemos "forma do conteúdo" por força de uma tradição linguística (HJELMSLEV, 2003, p. 53-64), mas também em função do poder de organização de uma experiência no corpo de um poema. A respeito de outro poema, ainda que pertencente a Prosas seguidas de Odes mínimas, Davi Arrigucci Jr. (1999, p.217) parece encontrar a mesma força de composição, com menções a medidas e limites como os que nortearam a nossa concepção alargada de aspecto. Se em nossas análises tratávamos de medidas e limites inscritos no texto, Arrigucci Jr. expande essas noções para o próprio fazer poético. Dada a natureza metalinguística dos poemas analisados, acreditamos ser bastante adequado e elucidador o paralelo entre a arquitetura interna dos poemas e a construção da própria poesia. A poesia recria em seu interior os limites com que se depara o homem. Assim, na inusitada coincidência, fazemos das suas palavras a nossa conclusão:

$\checkmark$ A poesia é uma ordem no caos de nossos dias, uma tentativa de organizar na forma breve da arte a experiência sem rumo certo. E dá a medida do humano frente ao limite.

\section{Referências}

ARRIGUCCI JR., David. Humildade, paixão e morte. São Paulo: Cia. das Letras, 1990.

ARRIGUCCI JR., David. Agora Tudo é História. In: Outros achados e perdidos. São Paulo: Cia. das Letras, 1999, p. 187-217.

BANDEIRA, Manuel. Estrela da vida inteira. Rio de Janeiro: Nova Fronteira, 1993.

BASTIDE, F. Aspectualisation. In: GREIMAS, Algirdas Julien; COURTÉS, Joseph (Org.). Sémiotique: dictionnaire raisonné de la théorie du langage. Paris: Hachette, 1986. Tomo 2, p. 19-24.

BOSI, Alfredo. O Livro do Alquimista. In: Céu, inferno. São Paulo: Duas Cidades/Ed. 34, 2003. p. 155-169.

FIORIN, José Luiz. As astúcias da Enunciação. As categorias de pessoa, espaço e tempo. São Paulo: Ática, 2002.

FORTUNA, Felipe. Miniatura em Si Maior. In: Escola de sedução: ensaios sobre poesia brasileira. Porto Alegre: Artes e Ofícios, 1991. p. 84-87.

GREIMAS, Algirdas Julien; COURTÉS, Joseph. Dicionário de semiótica. São Paulo: Contexto, 2011.

HJELMSLEV, Louis. Prolegômenos a uma teoria da linguagem. Tradução de J. Teixeira Coelho Netto. São Paulo: Perspectiva, 2003.

LEMOS, Carolina Lindenberg; TATIT, Luiz Augusto de Moraes. Entre expressões e conteúdos: do semissimbolismo às categorias tensivas. 2010. 122 f. Dissertação (Mestrado em Semiótica e Linguística Geral) - Faculdade de Filosofia, Letras e Ciências Humanas, Universidade de São Paulo, São Paulo, 2010. 
PAES, José Paulo. Poesia completa. Apresentação de Rodrigo Naves. São Paulo: Cia. das Letras, 2008.

PASCHE, Marcos Estevão Gomes. José Paulo Paes. Poeta como nenhum outro. 2009. $124 \mathrm{f}$. Dissertação (Mestrado em Letras Vernáculas - Literatura Brasileira) - Faculdade de Letras, Universidade Federal do Rio de Janeiro, Rio de Janeiro, 2009.

SECCHIN, Antonio Carlos. Um Poeta em Paz. In: Poesia e desordem. Escritos sobre poesia e alguma prosa. Rio de Janeiro: Topbooks, 1996. p. 121-124.
ZILBERBERG, Claude. Plaidoyer pour le tempo. In: FONTANILLE, Jaques (org.) Le devenir. Limoges: Pulim, 1995, p. 223-241.

ZILBERBERG, Claude. Razão e poética do sentido. Tradução Luiz Tatit, Ivã Carlos Lopes e Waldir Beividas. São Paulo: Edusp, 2006.

Recebido: 01 de fevereiro de 2016. Aprovado: 01 de setembro de 2016 Contato: carolina.lemos@gmail.com 